Tropical Journal of Pharmaceutical Research February 2014; 13 (2): 281-286

ISSN: $1596-5996$ (print); 1596-9827 (electronic) (C) Pharmacotherapy Group, Faculty of Pharmacy, University of Benin, Benin City, 300001 Nigeria.

All rights reserved.

\title{
Sensitive and Selective Reversed-Phase High Performance Liquid Chromatographic-UV Spectrophotometric Determination of Dextromethorphan and its CYP2D6 Mediated Metabolite, Dextrorphan in Human Urine
}

\author{
Benjamin U Ebeshi ${ }^{12^{*}}$, Obiageri O Obodozie ${ }^{3}$ and Oluseye 0 Bolaji ${ }^{2}$ \\ ${ }^{1}$ Department of Pharmaceutical \& Medicinal Chemistry, Faculty of Pharmacy, Niger Delta University, Wilberforce Island, \\ ${ }^{2}$ Department of Pharmaceutical Chemistry, Faculty of Pharmacy, Obafemi Awolowo University, Ile-Ife, ${ }^{3}$ Department of Medicinal \\ Chemistry \& Quality Control, National Institute for Pharmaceutical Research \& Development, Abuja, Nigeria
}

${ }^{*}$ For correspondence: Email: ben.beshi@gmail.com; Tel: +234-8059817538

Received: 4 December 2012

Revised accepted: 24 December 2013

\begin{abstract}
Purpose: To develop a simple, sensitive and selective method for the determination of dextromethorphan and its metabolite, dextrophan in human urine using reversed-phase high performance liquid chromatography with UV-spectrophotometric detection (RP-HPLC-UV).

Methods: Pre-column sample clean-up was carried out by liquid-liquid extraction of the analytes with chloroform: isopropanol (70:30) solution after alkalization of $1000 \mu \mathrm{L}$ sample and spiking of internal standard, morphine. The samples were chromatographed in a reversed-phase (C-18) ultra sphere silica ( $5 \mu \mathrm{m}$ particle size and $250 \times 4.6 \mathrm{~mm}$ I.D). The mobile phase consisted of methanol: acetonitrile: $0.5 \%$ w/V ammonium acetate (10:10:80) adjusted to $\mathrm{pH} 2.8$ with orthophosphoric acid and pumped through the column at $1 \mathrm{ml} / \mathrm{min}$ flow rate. The analytical method was validated for accuracy and precision as well as the recovery of the analytes, dextromethorphan and its metabolite, dextrophan over the concentration range of 0.20 to $5.0 \mu \mathrm{g} / \mathrm{ml}$.

Results: The standard curves were linear over the concentration range of 0.2 to $5.0 \mu \mathrm{g} / \mathrm{ml}$ for dextromethorphan and dextrorphan. The regression coefficients $\left(R^{2}\right)$ of the analytes were $>0.99$. The method was reproducible with coefficient of variation for the analytes being $<10 \%$. Dextromethorphan was well resolved from its metabolite, dextrorphan and the internal standard, morphine. The limits of detection of dextromethorphan and dextrorphan were $50 \mathrm{ng} / \mathrm{ml}$ and the recoveries and accuracies were greater than 85 and $90 \%$, respectively.

Conclusion: The analytical assay method exhibits good precision and selectivity and it was applied to the analysis of dextromethorphan and dextrorphan in urine for the assessment of CYP2D6 activity.
\end{abstract}

Keywords: Dextromethorphan, Dextrophan, Reversed-phase high performance liquid chromatography, CYP2D6 activity, Human urine

Tropical Journal of Pharmaceutical Research is indexed by Science Citation Index (SciSearch), Scopus, International Pharmaceutical Abstract, Chemical Abstracts, Embase, Index Copernicus, EBSCO, African Index Medicus, JournalSeek, Journal Citation Reports/Science Edition, Directory of Open Access Journals (DOAJ), African Journal Online, Bioline International, Open-J-Gate and Pharmacy Abstracts

\section{INTRODUCTION}

Dextromethorphan (DMP) is the methylated dextrorotatory analog of levorphanol (a $\mu$-opioid receptor agonist) and is chemically referred to as 3-methoxy-17-methylmorphinan. DMP is used for its antitussive properties for cough suppression and pain. The DMP metabolic pathway is mediated by $\mathrm{O}$-demethylation to its main metabolite, dextrophan (DP) via cytochrome P450 2D6 (CYP2D6), and N-demethylation to 3methoxymorphinan (3-MEM) via CYP3A4/5 [1]. 
3-MEM is further metabolized to 3-hydroxymorphinan (3-OHM) by CYP2D6. DP and 3-OHM are then eliminated via the kidneys after glucuronidation [2,3]. There are four phenotypic subpopulations that define the rate of drug metabolism by CYP2D6: individuals with poor $(P M)$, intermediate (IM), extensive (EM), and ultrarapid metabolizers (UM) [4]. DMP is a well established probe drug used to assess CYP2D6 function because it is relatively safe and readily available as an "over-the counter" medication, with only mild adverse effects [5,6]. CYP2D6 activity is predicted using the metabolic ratio (MR) from molar concentration of DMP/DP $[7,8]$.

Various methods have been described in literature for the determination of DMP and DP in urine, which include high-performance liquid chromatography (HPLC) with fluorescence detection [9-13], HPLC with ultraviolet detection [14], and gas chromatography with flame ionization [15], and mass spectrometric detection [16]. Specific quantitation was obtained in most of these methods but assay sensitivity was inadequate for the determination of the metabolites. Also, the lower limit of quantification of DMP was insufficient for the accurate determination of the DMP/DP ratio. There were several interferences from endogenous peaks under the chromatographic conditions specified in some of these methods thereby complicating the quantification of DMP or DP. Additionally, the sample preparation procedures described in these methods generally suffered from low analyte recoveries. Again, the assay selectivity in the presence of other metabolites was not mentioned and the selectivity of the method in urine samples originating from different subjects was not evaluated [17]. All these may adversely affect the determination of DMP, DP and other metabolites. Although the effectiveness of HPLCMS technique is very accurate, the equipment is rather costly. This study therefore aims to develop a simple, cost-effective and sensitive HPLC-UV method for the simultaneous quantitation of DMP and DP in urine samples in resource-limited settings.

\section{EXPERIMENTAL}

\section{Chemicals and reagents}

The chemicals and reagents used in this study were mostly procured from Sigma Aldrich (St. Louis, MO, USA) except where indicated. These include sodium chloride, sodium acetate, ammonium acetate, chloroform, isoprapanol, HPLC grade acetonitrile, HPLC grade methanol, sodium hydroxide, potassium dihydrogen phosphate and $\beta$-glucuronidase. Reference standards of dextromethorphan $\mathrm{HBr}$, dextrorphan-D-tartrate, morphine sulphate, and codeine were procured from Sigma Aldrich. Other reagents include methylated spirit (Fischer Scientific, USA), glacial acetic acid (BDH, UK), ammonium acetate (BDH, UK), orthophosphoric acid (BDH, UK), and dextromethorphan hydrobromide syrup (Zedex ${ }^{\circledR}$, Nigeria).

\section{Preparation of standard solutions}

Stock solutions of $100 \mu \mathrm{g} / \mathrm{ml}$ standard DMP and DP were prepared by dissolving $10 \mathrm{mg}$ of each separately in $100 \mathrm{ml}$ of distilled water. The stock solutions were serially diluted with water to give working standard concentrations of $0.2,0.5,1.0$, 2.0, 4.0, and $5 \mu \mathrm{g} / \mathrm{ml}$ for both DMP and DP. A stock solution of $1 \mathrm{mg} / \mathrm{ml}$ for the internal standard, morphine sulphate, was also prepared in water.

\section{Chromatographic conditions and equipment}

The liquid chromatographic system used was an Agilent 1100 series instrument, (Agilent Technologies, USA) made up of quaternary pumps, a gradient mixer (Agilent, Germany) with a system purge and a variable wavelength (200 800nm) uv-vis detector model CE1100 (Agilent, Japan) with an $18 \mu \mathrm{L}$ flow cell and detection was done at the wavelength of $278 \mathrm{~nm}$. Injection was by a Rheodyne model 7725 valve (Cotati, California, U.S.A.) fitted with a $20 \mu \mathrm{L}$ loop and an on-line vacuum degasser (Agilent, Japan). The HPLC was connected to a HP computer system and a printer. The column used was a reversedphase (C-18) ultra sphere silica with $5 \mu \mathrm{m}$ particle size and $250 \times 4.6 \mathrm{~mm}$ I.D (Beckman, USA). The mobile phase consisted of methanol: acetonitrile: $0.5 \% \mathrm{w} / \mathrm{v}$ ammonium acetate (10:10:80) pumped through the column at a flow rate of $1 \mathrm{ml} / \mathrm{min}$. The $\mathrm{pH}$ of the mobile phase was adjusted to 2.8 with orthophosphoric acid and the analytical run was performed at ambient temperature.

\section{Preparation of calibration standards and quality control samples for DMP and DP}

Blank urine $(1 \mathrm{ml})$ sample was each placed in six different extraction tubes and varying aliquots of the stock solutions $(100 \mu \mathrm{g} / \mathrm{ml})$ of DMP and DP were spiked to give concentrations of $0.2,0.5$, $1.0,2.0,4.0$, and $5 \mu \mathrm{g} / \mathrm{ml}$ for calibration standards and $0.2,0.5,1.0,2.0$, and $4.0 \mu \mathrm{g} / \mathrm{ml}$ for quality control (QC) samples. $20 \mu \mathrm{L}$ of the stock solution of the internal standard, morphine sulphate $(1 \mathrm{mg} / \mathrm{ml})$, was spiked to each tube. The samples were rendered alkaline with $1 \mathrm{M} \mathrm{NaOH}(0.5 \mathrm{ml})$ 
and whirlmixed for 1 min. Chloroform: isopropanol (70:30, $3 \mathrm{ml})$ solution was added to each of the tubes and whirlmixed for $1 \mathrm{~min}$ afterwhich the tubes were centrifuged at $2500 \mathrm{rpm}$ for $10 \mathrm{~min}$. The organic layer was transferred into another extraction tube. The extraction process was repeated and the pooled organic extract was evaporated to dryness in a water bath at $40{ }^{\circ} \mathrm{C}$. The residue was reconstituted in $100 \mu \mathrm{L}$ of $0.1 \mathrm{~N}$ $\mathrm{HCl}$ and whirlmixed before injecting $20 \mu \mathrm{L}$ onto the HPLC. The peak area ratio was plotted against the concentration of each of the compounds injected. The regression analysis was carried out using Microsoft Excel 2007. Values of the lower limit of quantitation (LLOQ) were calculated according to FDA guidelines for bioanalytical method validation [18] as at least five times the response compared to blank response and a precision of $20 \%$ and accuracy of $80-120 \%$.

\section{Determination of precision of the method for DMP and DP}

The assay procedure described under the preparation of calibration standards and quality control was repeated five times for $\mathrm{QC}$ samples within the same day (intra-day precision) and five times over four days (inter-day precision) both expressed as \%RSD values.

\section{Absolute recovery and accuracy for DMP and DP}

The recovery was computed by comparing peak areas obtained after extraction of QC samples from urine with peak area results after injecting working standard solutions at the same theoretical concentrations. The accuracy of the measurements was assessed based on replicate analysis of four QC samples for each compound in each run.

\section{Determination of DMP and DP in urine}

To $1 \mathrm{ml}$ of urine sample in a centrifuge tube, 20 $\mu \mathrm{L}$ of the internal standard was added and the mixture was incubated for $18 \mathrm{~h}$ with $0.5 \mathrm{ml}$ of 10 , 000 IU $\beta$-glucuronidase. After the incubation, DMP and its metabolite DP were extracted under alkaline conditions as previously described. The residue was reconstituted in $100 \mu \mathrm{L} 0.1 \mathrm{~N} \mathrm{HCl}$ and whirlmixed before $20 \mu \mathrm{L}$ was injected onto the HPLC. The metabolic ratio (MR) was calculated as the molar concentration ratio of dextromethorphan and its O-demethylated metabolite, dextrorphan in a 0 - 8 hour cumulated urine collection and was used to estimate CYP2D6 activity.

\section{Statistical analysis}

Results were expressed as mean \pm SD and RSD (\%) for the precision and recovery assays. Statistical analyses were carried out using GraphPad InStat software, version 2, and Microsoft Excel 2007 (Microsoft Corporation, USA) with $p<0.05$ as the level of significance.

\section{RESULTS}

\section{Chromatographic analysis of DMP and DP}

The retention time for DMP, DP and the internal standard MP were 8.7, 5.3 and $4.2 \mathrm{~min}$, respectively, as shown in Fig 1. A representative chromatogram of the blank urine sample spiked with $2 \mu \mathrm{g} / \mathrm{ml}$ of standard, DMP and DP and the internal standard (MP) is presented in Fig 2 .The retention times of DMP, DP and MP in the sample chromatograms corresponded to those obtained from the reference compounds by direct injection (Fig 1). These demonstrated that chromatographic peaks of DMP, DP and MP were well resolved with no interferences from endogenous substances in the matrix.

The limit of detection taken as the concentration giving a peak of at least five times the baseline noise was $20 \mathrm{ng} / \mathrm{ml}$ for both DMP and DP using $1 \mathrm{ml}$ sample, while the value of the lower limit of quantitation (LLOQ) calculated according to the FDA guidelines for bioanalytical method validation [18] was $50 \mathrm{ng} / \mathrm{ml}$ for both compounds.

\section{Calibration curves for DMP and DP}

The standard curve was a graph of the peak area ratio (y-axis) versus the concentration (x-axis) of each of the compounds and was linear over the concentration range of 0.2 to $5.0 \mu \mathrm{g} / \mathrm{ml}$ for DMP and $\mathrm{DP}$, in urine. The regression equations for the calibration curves for DMP and DP were $y=$ $1.537 x-0.115$ and $y=0.681 x-0.265$, respectively with the regression coefficients $\left(R^{2}\right)$ being 0.995 and 0.998 for DMP and DP, respectively, which allowed for accurate reading of the concentrations of all the test samples.

\section{Precision of the analytical Method for DMP and DP}

The RSD\%, which is a measure of the precision ranged from 4.29 to $7.80 \%$ for intra-day run and 1.90 to $5.26 \%$ for inter-day assay for DMP, while RSD\% for DP ranged from 1.43 to $7.2 \%$ and 


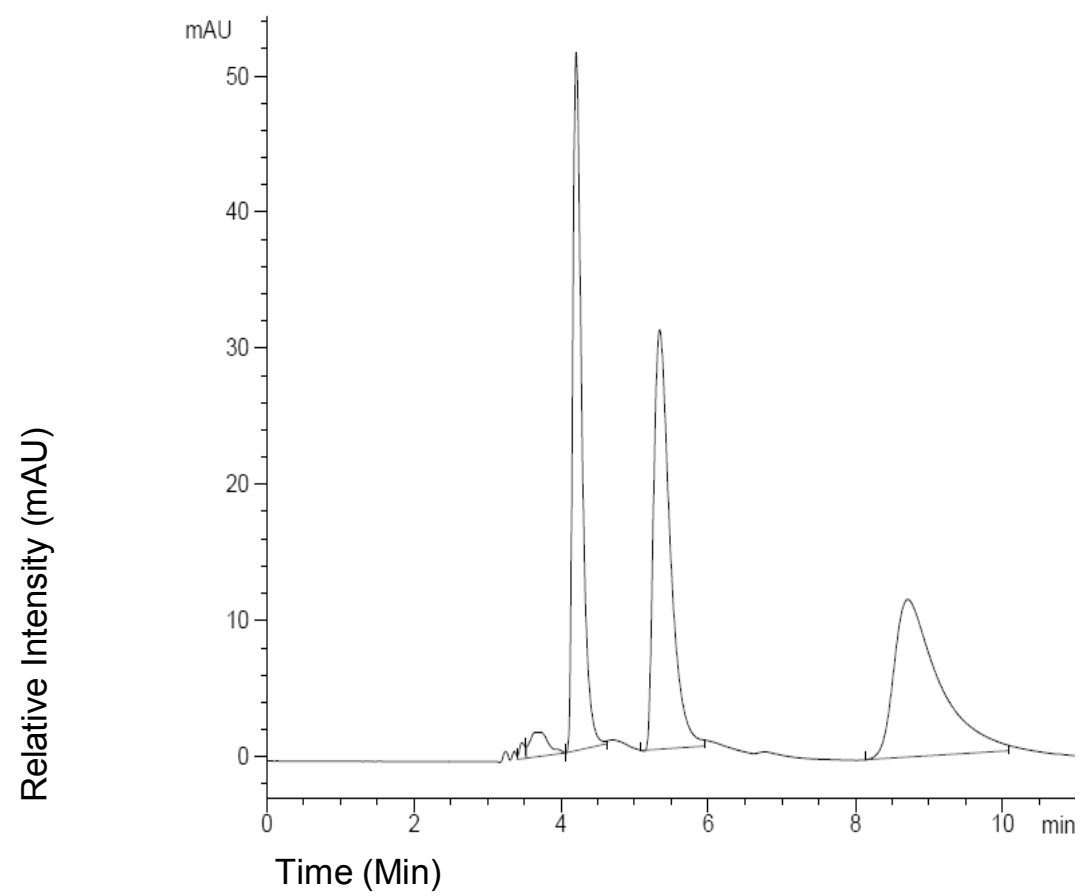

Fig 1: HPLC chromatogram following direct injection of test samples containing $2 \mu \mathrm{g} / \mathrm{ml}$ of DMP, DP and internal standard, MP. The peak eluting at 4.2 min represents MP while the peaks at 5.3 and 8.7 mins represents DP and DMP, respectively

1.85 to $5.23 \%$ for intra-day and inter-day precision, respectively as shown in Table 1.

\section{Recovery and Accuracy of DMP and DP}

The recovery of DMP and DP from spiked urine following extraction ranged from 84.8 to $104.8 \%$, while the accuracy of the analytical method ranged from 92 to $106 \%$ as shown in Table 1.

\section{DISCUSSION}

The analytical assay method developed in this study gave a good resolution of dextromethorphan and its main metabolite, dextrorphan. When ten blank urine samples obtained from different individuals were hydrolyzed, cleaned up and injected onto the HPLC to check for endogenous interferences, no endogenous compound was found to interfere with the DMP and DP. Also, few structurally related compounds such as codeine as well as some inhibitors of CYP2D6 like propranolol were assessed to check for possible interferences. None of these drugs interfered with the determination of the analytes. The analytical method therefore gave a good resolution of DMP, DP as well as the internal standard MP, thus facilitating accurate determination of the drug and its metabolite.
The LLOQ for DMP and DP in urine was 50 $\mathrm{ng} / \mathrm{ml}$, which made it possible to monitor the unchanged drug and its metabolite in the samples. The method was found to be reproducible, as indicated by values obtained for RSD (<10\%) for DMP and DP. The recoveries and accuracies for the analytes ranged from 84.8 to $104.8 \%$ and 89 to $110 \%$, respectively, indicating that the method was quite accurate and sensitive. The stability of QC samples was evaluated for samples stored at $-20{ }^{\circ} \mathrm{C}$ for 4 months; at room temperature for $24 \mathrm{~h}$; and after three freeze-thaw cycles. Stability of treated samples was also assessed after $24 \mathrm{~h}$ [18]. In all of the conditions, samples preserved their potency (>90 \%) during the mentioned periods.

This method emphasized off-column pretreatment as a necessary panacea for effective extraction and quantitation of DMP and DP in urine. In this study, the choice of chloroform/isopropanol as the extracting solvent resulted in some improved recovery of DMP compared to previous reports [14,19]. The analytical method employed in this study is one of the few methods that can detect DMP and its metabolite DP. Besides, the sample preparation procedures described in some previous methods generally suffered from low analyte recoveries $[15,20]$ and in most cases, the selectivity of these methods in the presence of a number of other metabolites of DMP was not clearly established. 


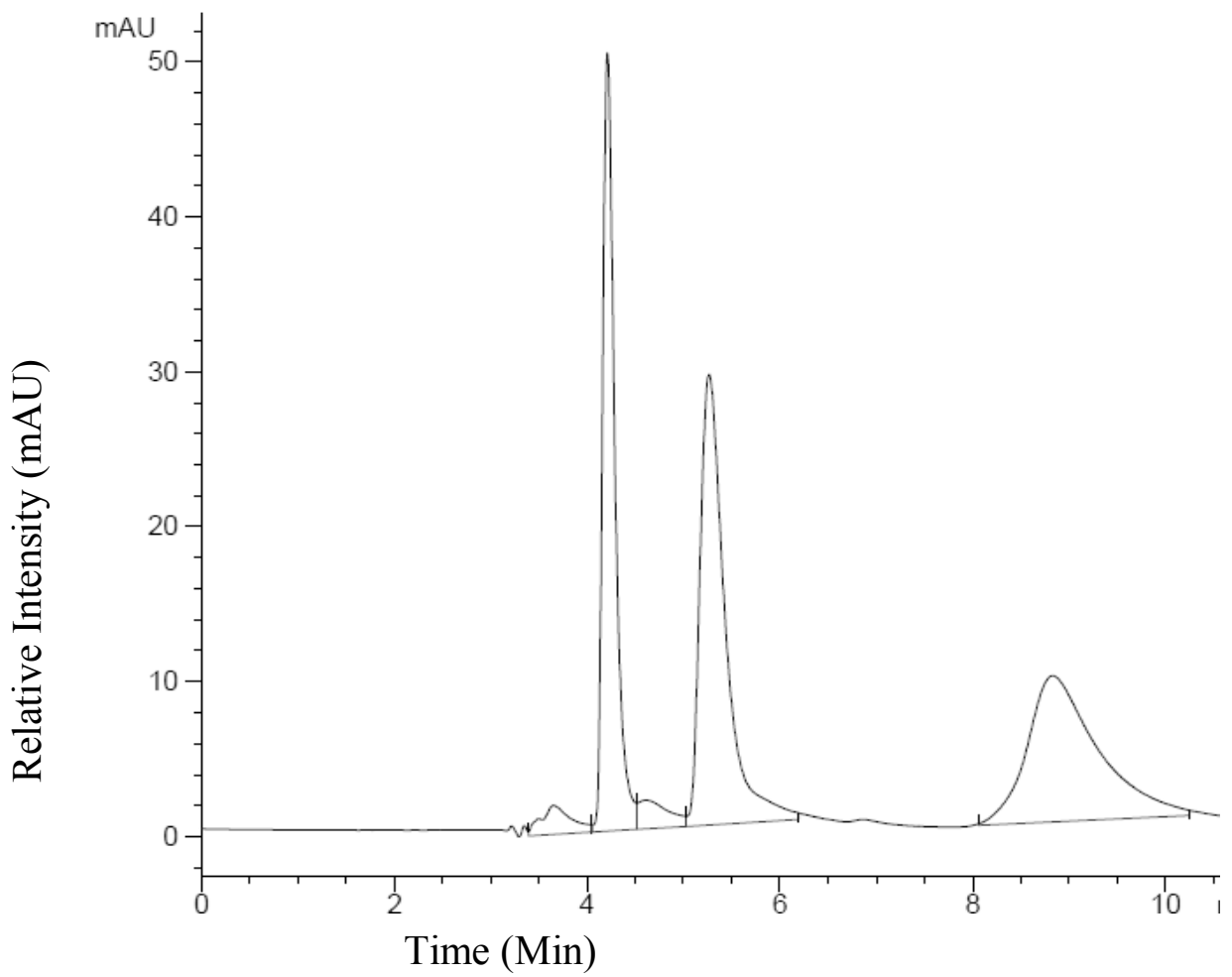

Fig 2: HPLC Chromatogram of spiked urine containing $2 \mu \mathrm{g} / \mathrm{ml}$ each of DMP, DP and internal standard, MP. The peak eluting at 4.2 min represents MP while the peaks at approximately 5.3 and 8.8 min represent DP and DMP, respectively.

Table 1: Intra- and inter-day assay variability, accuracy and recovery of dextromethorphan and dextrorphan from urine

\begin{tabular}{|c|c|c|c|c|c|c|c|c|c|}
\hline & \multirow[b]{2}{*}{$\begin{array}{l}\text { Expecte } \\
\text { d conc. } \\
(\mu \mathrm{g} / \mathrm{ml})\end{array}$} & \multicolumn{3}{|c|}{ Intra-day precision $(n=5)$} & \multicolumn{3}{|c|}{ Inter-day precision $(n=5)$} & \multicolumn{2}{|c|}{$\begin{array}{l}\text { Analyte recovery } \\
(n=5)\end{array}$} \\
\hline & & $\begin{array}{l}\text { Mean } \\
\text { observed conc } \\
\pm S D(\mu g / m l)\end{array}$ & $\begin{array}{l}R S D \\
(\%)\end{array}$ & $\begin{array}{l}\text { Accuracy } \\
(\%)\end{array}$ & $\begin{array}{l}\text { Mean } \\
\text { observed } \\
\text { conc } \pm S D \\
(\mu g / m l)\end{array}$ & RSD (\%) & $\begin{array}{l}\text { Accuracy } \\
(\%)\end{array}$ & $(\%) \pm S D$ & $R^{\prime} D(\%)$ \\
\hline & 0.2 & $0.19 \pm 0.015$ & 7.80 & 95 & $0.19 \pm 0.01$ & 5.26 & 95 & $85.3 \pm 0.54$ & 0.63 \\
\hline Dextromethorphan & $\begin{array}{l}0.5 \\
1.0 \\
2.0\end{array}$ & $\begin{array}{l}0.53 \pm 0.031 \\
1.05 \pm 0.045 \\
1.78 \pm 0.082\end{array}$ & $\begin{array}{l}5.81 \\
4.29 \\
4.6\end{array}$ & $\begin{array}{l}106 \\
105 \\
89\end{array}$ & $\begin{array}{l}0.55 \pm 0.02 \\
1.02 \pm 0.034 \\
1.84 \pm 0.035\end{array}$ & $\begin{array}{l}4.05 \\
3.33 \\
1.90\end{array}$ & $\begin{array}{l}110 \\
102 \\
92\end{array}$ & $\begin{array}{l}87.1 \pm 1.02 \\
90.4 \pm 0.76 \\
84.8 \pm 1.28\end{array}$ & $\begin{array}{l}1.17 \\
0.84 \\
1.51\end{array}$ \\
\hline & 0.2 & $0.18 \pm 0.013$ & 7.2 & 90 & $0.21 \pm 0.011$ & 5.23 & 105 & $90.6 \pm 1.08$ & 1.19 \\
\hline Dextrorphan & $\begin{array}{l}0.5 \\
1.0 \\
2.0 \\
\end{array}$ & $\begin{array}{l}0.49 \pm 0.01 \\
0.98 \pm 0.04 \\
2.11 \pm 0.03 \\
\end{array}$ & $\begin{array}{l}2.5 \\
4.1 \\
1.43 \\
\end{array}$ & $\begin{array}{l}98 \\
98 \\
106 \\
\end{array}$ & $\begin{array}{l}0.51 \pm 0.023 \\
1.04 \pm 0.042 \\
2.06 \pm 0.038 \\
\end{array}$ & $\begin{array}{l}4.50 \\
4.04 \\
1.85 \\
\end{array}$ & $\begin{array}{l}102 \\
104 \\
103 \\
\end{array}$ & $\begin{array}{l}90.8 \pm 1.06 \\
94.2 \pm 0.80 \\
104.8 \pm 1.12 \\
\end{array}$ & $\begin{array}{l}1.17 \\
0.85 \\
1.07 \\
\end{array}$ \\
\hline
\end{tabular}

\section{CONCLUSION}

The HPLC method described is a simple, sensitive and cost-effective assay technique for the determination of dextromethorphan and its CYP2D6-mediated metabolite, dextrorphan, in urine. The main advantage of the method is the use of a simple liquid-liquid extraction process for sample clean-up prior to chromatographic protocol with good analyte recovery. The newly developed method allowed the simultaneous determination of dextromethorphan and its main metabolite, dextrorphan; it is also suitable for separating CYP2D6 phenotypes.

\section{ACKNOWLEDGEMENT}

The authors acknowledge the technical assistance of Theophillus Ache and the cooperation of the staff of the Department of Medicinal Chemistry \& Quality Control, National Institute for Pharmaceutical Research and Development Idu-Abuja, Nigeria.

\section{REFERENCES}

1. $Y u A$, Dong $H$, Lang $D$, Haining RL. Characterization of dextromethorphan $\mathrm{O}-$ and $\mathrm{N}$-demethylation

Trop J Pharm Res, February 2014; 13(2): 285 
catalyzed by highly purified recombinant human CYP2D6. Drug Metab. Dispos. 2001; 29(11): 1362-1365

2. Afshar $M$, Rouini MR, Amini M. Simple chromatography method for simultaneous determination of dextromethorphan and its main metabolites in human plasma with fluorimetric detection. J. Chromatogr. B 2004; 802(2): 317322.

3. Lutz $U$, Volkel W, Lutz RW, Lutz WK. LC-MS/MS analysis of dextromethorphan metabolism in human saliva and urine to determine CYP2D6 phenotype and individual variability in $\mathrm{N}$ demethylation and g-lucuronidation. J. Chromatogr. B 2004; 813(1-2): 217-225.

4. Grant RW. Drug metabolism and variability among patients in drug response. New Engl. J. Med. 2005; 352: 2211-2221.

5. Levy $R H$, Thummel KE, Trager WE, Hansten PD, Eichelbaun M. Metabolic Drug Interactions, Taylor RB (ed), Lippincott Williams \& Wilkins, Philadelphia, USA; 2000. p. 115-133.

6. Aiming $Y U$, Haining $R L$. Comparative contribution to dextromethorphan metabolism by Cytochrome P450 isoforms in Vitro: can dextromethorphan be used as a dual probe for both CYP2D 6 and CYP3A activities? Drug Metab. Dispos. 2001; 29(11): 1514-1520.

7. Schmid B, Bircher J, Preisig R, Kupfer A. Polymorphic dextromethorphan metabolism: co-segregation of oxidative O-demethylation with debrisoquin hydroxylation. Clin. Pharmacol. Ther. 1985; 38(6): 618-624.

8. Capon DA, Bochner F, Kerry N, Mikus G, Danz C, Somogyi, $A A$. The influence of CYP2D6 polymorphism and quinidine on the disposition and antitussive effect of dextromethorphan in humans. Clin. Pharmacol. Ther. 1996; 60(3): 295-307.

9. Achari RG, Ederma HM, Chin D, Oles SR. Determination of dextromethorphan in biological fluids by liquid chromatography by using semimicrobore columns. J. Pharm. Sci. 1984; 73(12): 1821-1822.

10. East $T$, Dye, D. Determination of dextromethorphan and metabolites in human plasma and urine by high-performance liquid chromatography. J. Chromatogr. 1985; 338(1): 99-112.

11. Fossati A, Vimercati G. Caputo R, Citerio L, Ceriani $R$ Vaenti $M$. Comparative pharmacokinetics of oral dextromethorphan and dextrorphan in the rabbit. Arzneimittelforschung/Drug Res. 1993; 43(12). 1337-1340.

12. Chen ZR, Somogyi AA, Bochner F. Simultaneous determination of dextromethorphan and three metabolites in plasma and urine using highperformance liquid chromatography with application to their disposition in man. Ther. Drug Monit. 1990; 12(1): 97-104.

13. Bendriss EK, Markoglou N, Wainer IW. Highperformance liquid chromatography assay for simultaneous determination of dextromethorphan and its main metabolites in urine and in microsomal preparations. J. Chromatogr. B 2001; 754(1): 209215.

14. Park YH, Kullberg MP, Hinsvark ON. Quantitative determination of dextromethorphan and three metabolites in urine by reversed-phase high performance liquid chromatography. J. Pharm. Sci. 1984; 73(1): 24-29.

15. Wu YJ, Cheng YY, Zeng S, Ma MM. Determination of dextromethorphan and its metabolite dextrorphan in human urine by capillary gas chromatography without derivatization. J. Chromatogr. B 2003; 784(2): 219-224.

16. Baumann $P$, Jonzier-Perey $M . \quad G C$ and GC-MS procedures for simultaneous phenotyping with dextromethorphan and mephenytoin. Clin. Chem. Acta 1988: 171(2-3): 211-222.

17. Vengurlekar SS, Heitkamp J, McCush F, Velagaleti PR, Brisson JH, Bramer SL. A sensitive LC-MS/MS assay for the determination of dextromethorphan and metabolites in human urine--application for drug interaction studies assessing potential CYP3A and CYP2D6 inhibition. J. Pharm. Biomed. Anal. 2002; 30(1): 113-124.

18. FDA. Guidance for Industry: Bioanalytical Method Validation (ucm070107). 2001; [cited 2012 February 15 http://www.fda.gov/downloads/Drugs/ GuidanceCompilanceRegulatory/nformation/Guida nces.

19. Lin SY, Chen $\mathrm{CH}$, Ho HO, Chen $\mathrm{HH}$, Sheu MT. Simultaneous analysis of dextromethorphan and its three metabolites in human plasma using an improved HPLC method with fluorometric detection. J. Chromatogr. B. 2007; 859(1): 141146.

20. Loos WJ, de Graan AJ, de Bruijn $P$, van Schaik $R H$, van Fessem MA, Lam MH, Mathijssen RH, Wiemer EA. Simultaneous quantification of dextromethorphan and its metabolites dextrorphan, 3-methoxymorphinan and 3-hydroxymorphinan in human plasma by ultra performance liquid chromatography/tandem triple-quadrupole mass spectrometry. J. Pharm. Biomed. Anal. 2011; 54(2): 387-394. 